\title{
Cultural adaptation and validation of an instrument about nursing critical thinking skills
}

\author{
Adaptação cultural e validação de instrumento sobre habilidades de pensamento crítico em enfermagem \\ Adaptación cultural y validación de un instrumento sobre habilidades de pensamiento crítico en enfermería
}

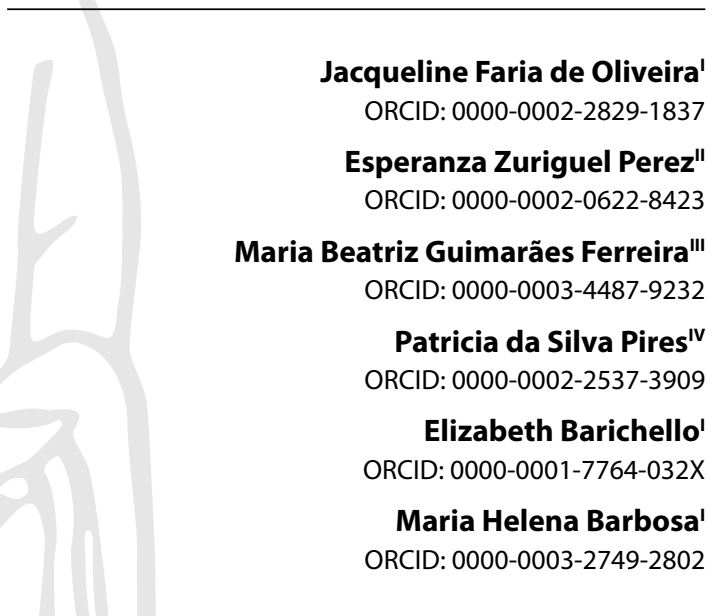

'Universidade Federal do Triângulo Mineiro. Uberaba, Minas Gerais, Brazil.

"University Hospital Vall d'Hebron. Barcelona Catalunha, Espanha.

I'Universidade Federal de Uberlândia. Uberlândia, Minas Gerais, Brazil.

"Universidade Federal da Bahia. Vitória da Conquista Bahia, Brazil.

How to cite this article:

Oliveira JF, Zuriguel-Perez E, Ferreira MBG, Pires PS, Barichello E, Barbosa MH. Cultural adaptation and validation of an instrument about nursing critical thinking skills.

Rev Bras Enferm. 2021;74(2):e20200720. https://doi.org/10.1590/0034-7167-2020-0720

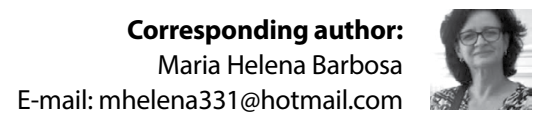

EDITOR IN CHIEF: Antonio José de Almeida Filho ASSOCIATE EDITOR: Álvaro Sousa

Submission: 08-12-2020 Approval: 10-27-2020

\begin{abstract}
Objectives: to validate the Nursing Critical Thinking in Clinical Practice Questionnaire regarding cultural aspects and metric properties. Methods: a methodological research carried out through cross-cultural adaptation, face and content validity, dimensional construct and known groups validity, test-retest reliability and internal consistency. 511 nurses from four hospitals participated in the study, of which 54 participated in retest. Results: the instrument validation for Brazilian Portuguese maintained equivalences, according to the original version. The dimensional validity demonstrated adjustment to the tetrafactorial structure of the original version $(\mathrm{GFI}=0.69)$. There were statistically significant differences in critical thinking skills between nurses with graduate degrees and who undertook training, reading articles, developing research and working in an institution with a longer time implementation of the Nursing Process. The instrument showed temporal stability (ICC 073-0.84; $p<0.001$ ) and adequate internal consistency ( $\alpha=0.97$ ). Conclusions: the instrument proved to be valid and reliable for the studied population.
\end{abstract}

Descriptors: Nursing; Thinking; Nursing Process; Validation Study; Factor Analysis, Statistical.

\section{RESUMO}

Objetivos: realizar a validação do instrumento Nursing Critical Thinking in Clinical Practice Questionnaire quanto a aspectos culturais e propriedades métricas. Métodos: pesquisa metodológica, realizada por meio de adaptação transcultural, validade de face e conteúdo, validade de construto dimensional e de grupos conhecidos, confiabilidade teste-reteste e consistência interna. Participaram do estudo 511 enfermeiros de quatro hospitais, dos quais 54 participaram do reteste. Resultados: a validação do instrumento para o português brasileiro manteve as equivalências, conforme versão original. A validade dimensional demonstrou ajuste à estrutura tetrafatorial da versão original $(\mathrm{GFI}=0,69)$. Observaram-se diferenças estatisticamente significativas de habilidades do pensamento crítico entre enfermeiros com pós-graduação e que realizaram capacitações, com leitura de artigos, desenvolvimento de pesquisas e atuação em instituição com maior tempo de implantação do Processo de Enfermagem. Instrumento apresentou estabilidade temporal $(\mathrm{CCl}=073-0,84$; $p<0,001)$ e adequada consistência interna $(\alpha=0,97)$. Conclusões: instrumento se mostrou válido e confiável para população estudada.

Descritores: Enfermagem; Pensamento; Processo de Enfermagem; Estudo de Validação; Análise Fatorial.

\section{RESUMEN}

Objetivos: realizar la validación del Nursing Critical Thinking in Clinical Practice Questionnaire sobre aspectos culturales y propiedades métricas. Métodos: investigación metodológica realizada a través de adaptación transcultural, validez de rostro y contenido, validez de constructo dimensional y grupos conocidos, confiabilidad test-retest y consistencia interna. En el estudio participaron 511 enfermeras de cuatro hospitales, de las cuales 54 participaron en la nueva prueba. Resultados: la validación del instrumento para portugués brasileño mantuvo las equivalencias, según la versión original. La validez dimensional demostró ajuste a la estructura tetrafactorial de la versión original $(\mathrm{GF}=0,69)$. Hubo diferencias estadísticamente significativas en las habilidades de pensamiento crítico entre enfermeros con posgrados, que completaron su formación, leyendo artículos, desarrollando investigaciones y trabajando en una institución con un tiempo de implementación más largo del Proceso de Enfermería. El instrumento mostró estabilidad temporal (ICC $=073-0,84 ; p<0,001$ ) y adecuada consistencia interna $(a=0,97)$. Conclusiones: el instrumento resultó válido y confiable para la población estudiada. Descriptores: Enfermería; Pensamiento; Proceso de Enfermería; Estudio de Validación; Análisis Factorial. 


\section{INTRODUCTION}

The social, political, economic and cultural aspects have changed with globalization, also impacting the nursing work process evolution. A scenario with greater complexity of care, linked to technological innovations and greater demands in relation to quality of care, requires changes in the curriculum proposal, with a training of professionals with a profile in which greater reflection, self-criticism and professional responsibility develop ${ }^{(1)}$.

To meet changing profession, nurses must maintain a level of skills and competencies essential to their performance ${ }^{(2)}$. This requires professionals to be active, purposeful, creative, analytical, flexible, with logical reasoning and able to continuously update information used effectively to solve health problems ${ }^{(3)}$.

Critical thinking (CT) consists of skills that enable nurses to develop the ability to interpret and analyze problems and situations, assess and make inferences, foresee results and implement effective actions ${ }^{(4)}$.

Before developing $\mathrm{CT}$, it is necessary to identify the level of thought presented and what skills need to be developed. Using instruments that assess $\mathrm{CT}$ is a starting point for interventions that promote its development ${ }^{(5)}$.

Despite the variety of instruments available in the scientific literature for $\mathrm{CT}$ assessment, a Brazilian study that assessed graduate nurses showed that using a non-specific instrument for nursing was a study limitation, as it is generic and does not allow CT assessment in specific clinical situations ${ }^{(6)}$.

The Nursing Critical Thinking in Clinical Practice Questionnaire $(\mathrm{N}-\mathrm{CT}-4 \text { Practice })^{(7)}$ is characterized as a specific nursing instrument and aims to assess the level of CT skills of nurses working in clinical field. This instrument allows a CT assessment based on the interrelation of individual patterns of behavior, on the intellectual skills related to the nursing course, on the skills that allow establishing bonds with patients in clinical environment, and on professional team members and knowledge procedures that are part of professional performance ${ }^{(7)}$.

Identifying CT skills favors response to clinical problems, contributing to the strengthening of safe and quality care. It is also noteworthy lack of research in the Brazilian literature on specific nursing measurement instruments to investigate the components of nurses' $\mathrm{CT}$. Considering this, the following question was asked: is the N-CT-4 Practice, validated for the Brazilian context, a reliable instrument to identify the level of CT skills of nurses working in clinical practice?

\section{OBJECTIVES}

To validate the Nursing Critical Thinking in Clinical Practice Questionnaire regarding cultural aspects and metric properties.

\section{METHODS}

\section{Ethical aspects}

This investigation started after approval by a Research Ethics Committee, following the precepts of Resolution 466/2012 of the Brazilian National Health Council (CNS - Conselho Nacional de Saúde). The Informed Consent Form was signed by all participants.

\section{Study design, period, and location}

This is a methodological research, which aims to translate, culturally adapt and assess the metric properties of the N-CT-4 Practice instrument. This research was initiated after authorization and agreement from the main author of the instrument. To guide the research conduct, guidelines for observational studies were adopted, called Strengthening the Reporting of Observational Studies in Epidemiology (STROBE) checklist: cross-sectional studies ${ }^{(8)}$.

The process of cultural adaptation and assessment of metric properties took place over a period of one year. Translation, synthesis, and face and content validation took place between January and June 2019. Construct validation was performed by applying the instrument in four university hospitals in the cities of Uberaba, Uberlândia, and Porto Alegre. This stage took place between July and September 2019.

\section{Sample; inclusion and exclusion criteria}

Care and management nurses working at different hospital units were included, with a minimum of 1 month of employment in the sector. Hospital A assisted 27 municipalities and had 302 high and medium complexity active beds. Hospital B had 520 beds and was a reference in medium and high complexity for 86 municipalities. Hospital $C$ was a pioneer in implementing the Nursing Process in Brazil and had 842 beds with high and medium complexity care. Hospital D had 221 beds and performed high and medium complexity care. Hospital A had a population of 250 nurses, B, 234, C, 640. and D, 62 nurses. It should be noted that two nurses worked at two participating hospitals, being counted only once in the research.

To calculate the sample size, the recommendation of at least 200 participants was considered to carry out factor analysis ${ }^{(9)}$. However, 511 nurses participated in the study (204 from Hospital A, 160 from Hospital B, 94 from Hospital C, and 53 from Hospital D), a number well above this recommended minimum, out of a total of 1,186 individuals initially recruited. Thus, 675 nurses did not participate in the study ( 18 are assigned to hospital institutions, however they are attending activities in external teaching or health units that are partners of the hospital; 66 were on some kind of leave or vacation; one was fired; 35 refused to participate; 555 did not respond to email or did not return the answered instrument after third attempt). For the test-retest reliability analysis, the sample size calculation was 54 participants.

\section{Study protocol}

\section{Stage 1: Cross-cultural adaptation}

For cultural adaptation, the methodology proposed by Ferrer and collaborators was used ${ }^{(10)}$. This framework consists of six steps: translation into Brazilian Portuguese; synthesis and obtaining the first consensus of the Brazilian Portuguese version; assessment by a committee of judges and semantic analysis of items; back-translation; obtaining consensus on the Spanish versions; comparison to the original version.

Translation was performed by two independent Brazilian translators, fluent in Spanish, because the instrument was from 
Spain, Barcelona. Each translator prepared a version in Brazilian Portuguese, which was later consolidated into a single version, after consensus among researchers and translators. The first Brazilian Portuguese version was assessed by a committee of judges. Nurses with at least a PhD, with experience in the CT field in nursing, Nursing Process or clinical reasoning and diagnosis and with a command of Spanish composed the committee. After selecting the nurses who met the inclusion requirements for composing the committee of judges, an invitation was sent via email to participate in the research. The committee was composed of five nurses. In this stage, the committee assessed cultural, semantic, conceptual, and idiomatic equivalences, as well as face and content validities of the original version with the translated one. Only changes were adopted that obtained at least $80 \%$ agreement among judges.

All judges requested maintenance of the original layout of the instrument and changes to some items. Nineteen changes were made, such as changing word order, adding articles and changing words for a better understanding of an item (i.e. "distinto" (distinct) by "diferente" (different)). The single version plus the modifications suggested by the committee of judges was sent to two translators living in Brazil, whose mother tongue was Spanish. The translators individually carried out back-translations, and, from the two versions, consensus of the back-translated version for the Final Spanish Version was established. The Final Spanish Version and the Final Brazilian Portuguese Version were submitted for assessment by the main author. After approval, the validation process was continued.

\section{Step 2: Data collection}

The instruments were applied via e-mail using an electronic assessment form (questionnaire), available in a link, in three stages. The first was the Informed Consent Form to participate in the study; the second the instrument for sociodemographic and professional characterization $^{(11)}$; the third the N-CT-4 Practice - Brazilian Portuguese version. For nurses whose e-mail was not available, data collection was carried out in person. Thus, 94 nurses answered the instrument by email, and 417 in person by self-completion.

N-CT-4 Practice was designed based on Alfaro-LeFevre's theoretical model, exploring four CT components: personal characteristics, intellectual or cognitive skills, interpersonal and self-management skills, and technical skills. It consists of 109 affirmative items and organized into these four dimensions. The response format is a Likert-type questionnaire of four points, from never to almost never (one), always or almost always (four), in which professionals respond to the frequency they have a certain skill in their clinical practice.

The instrument's overall score is obtained by adding the scores of all items, ranging from 109 to 436 points. The higher the score, the higher the skill levels of nurses' $\mathrm{CT}$. The original study considers the level of CT skills to be low with scores of 328.6 or lower; moderate level, from 328.7 to 395.3; high level, 395.4 and more. The score for each dimension is also observed. The Personal Dimension is composed of 39 items, and their total scores can vary from 39 to 156; the Intellectual and Cognitive Dimension is made up of 44 items, and its total scores range from 44 to 176; the Interpersonal and Self-Management Dimension consists of 20 items, and its total scores range from 20 to 80; the Technical Dimension is composed of six items, and its total scores range from 6 to $24^{(7)}$.

\section{Step 3: Assessment of metric properties}

The validity of the dimensional construct was verified by confirmatory factor analysis and that of the construct by assessment of known groups, which were defined by workplace characteristics (hospitals with shorter and longer time for implementing the Nursing Process) and professional criteria and academics.

Test-retest reliability was adopted for the present study considering an interval of two weeks, as proposed by the study of the original instrument. The calculation of the instrument's internal consistency was also performed.

\section{Analysis of results, and statistics}

For data consolidation, a descriptive analysis of the instrument items was performed. To assess the construct's dimensionality, confirmatory factor analysis was used. To assess the known groups, comparisons of the mean scores of the dimensions were performed, using the Student's t test for independent samples. Cohen's d was used in order to classify the size of the difference between means, interpreted as small $(\geq 0.20$ to $<0.50)$, moderate $(\geq 0.50$ to $<0.79)$, and large $(\geq 0.80)^{(12)}$. Test-retest reliability was assessed by intraclass and Pearson correlation coefficients. The correlations' size was classified as weak $(0<r<0.30)$, moderate $(0.3 \leq r<0.5)$, and strong $(r \geq 0.5)$. A value above 0.70 was considered adequate for the Intraclass Correlation Coefficient (ICC) ${ }^{(13)}$. The evaluation of the internal consistency of the instrument items was measured by Cronbach's alpha, with admissible values $>0.70$. Statistical analyzes considered a significance level of $5 \%(a=0.05)^{(13)}$.

\section{RESULTS}

Of the 511 participating nurses, 431 (84.3\%) were female and $253(49.5 \%)$ were married. The mean age was $38.96(S D=8.19)$ years, (minimum of 22 and maximum of 64 years). As for academic training and qualification, 283 (55.4\%) attended undergraduate courses at a public educational institution, 329 (64.4\%) had a specialization and 140 (26.9\%) had master's degree and PhD.

Most nurses read scientific articles (90.6\%), have already developed some type of research (70.3\%) and did not attend training on research use in clinical practice $(84.5 \%)$ and on search for evidence scientific (52.4\%) (Table 1).

Table 1 - Sample distribution according to training and research, Uberaba, Minas Gerais, Brazil, 2019, (N=511)

\begin{tabular}{lc}
\hline Variables & $\mathbf{n}(\%)$ \\
\hline $\begin{array}{l}\text { Did you attend training on research results use in practice? } \\
\quad \text { Yes }\end{array}$ & $79(15.5)$ \\
$\quad$ No & $432(84.5)$ \\
Did you attend training in search of scientific evidence? & \\
$\quad$ Yes & $243(47.6)$ \\
$\quad$ No & $268(52.4)$ \\
Do you read scientific articles? & \\
$\quad$ Yes & $463(90.6)$ \\
$\quad$ No & $47(9.2)$ \\
Do you develop or have you already developed research? & \\
$\quad$ Yes & $359(70.3)$ \\
$\quad$ No & $152(29.7)$ \\
\hline
\end{tabular}




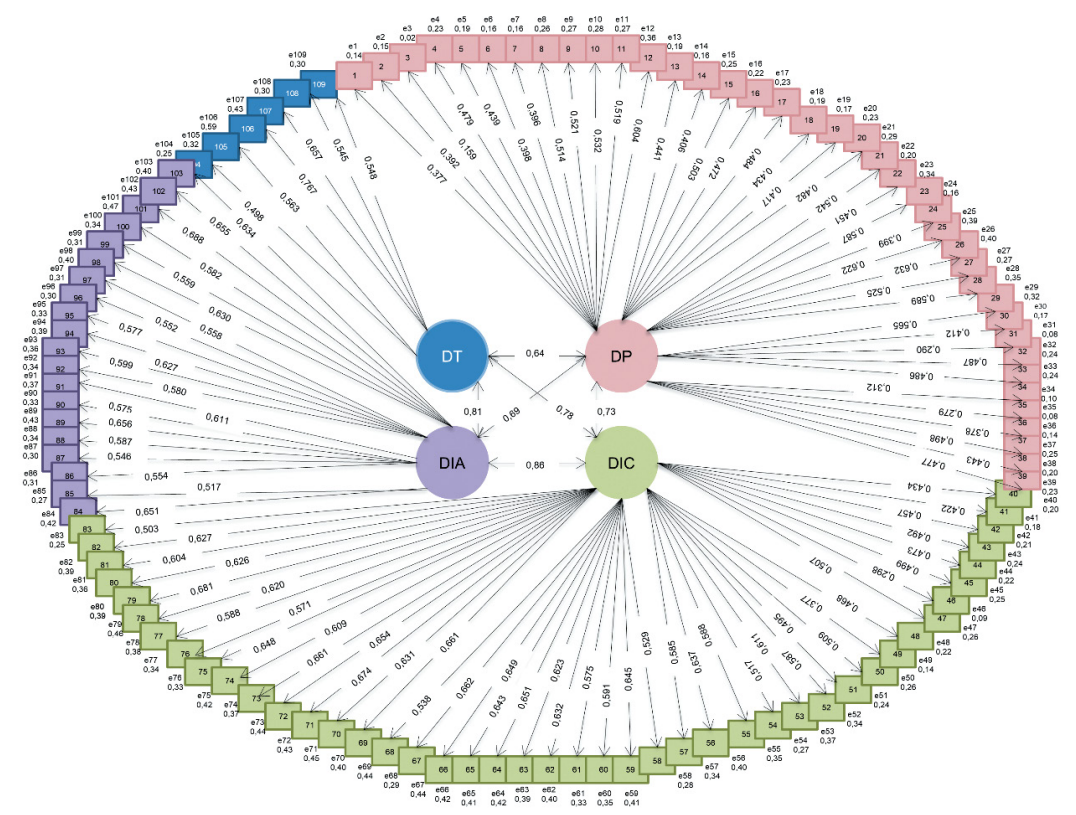

Note: TD - Technical Dimension; PD - Personal Dimension; ISMD - Interpersonal and Self-Management Dimension; ICD - Intellectual and Cognitive Dimension.

Figure 1 - Illustrative representation of the confirmatory factor analysis of the Nursing Critical Thinking in Clinical Practice Questionnaire, Uberaba, Minas Gerais, Brazil, 2019

As for N-CT-4 Practice scores presented by nurses, the means were 122.86 in the Personal Dimension, 149.1 in the Intellectual and Cognitive Dimension, 66.62 in the Interpersonal and SelfManagement Dimension, and 20.87 in the Technical Dimension. The mean instrument's overall score was 360.09 .

Most $(315 ; 61.6 \%)$ nurses in this study had a moderate level of CT skills, followed by low $(101 ; 19.8 \%)$ and high $(95 ; 18.6 \%)$ skills.

The dimensional construct validity of the N-CT-4 Practice, determined from confirmatory factor analysis, is shown in Figure 1.

The Personal Dimension presented factorial loads from 0.159 to 0.632 ; the Intellectual and Cognitive Dimension, from 0.377 to
0.674; the Interpersonal and Self-Management Dimension, from 0.517 to 0.688 ; the Technical Dimension, from 0.498 to 0.767 . Furthermore, in this analysis, all items showed statistical significance $(p<0.05)$.

The results showed model adjustment indicators. Chi-square value was $x^{2}(5,733)=11,064.551$, with $\mathrm{p}<0.001$, which made the hypothesis of equality of variance-covariance matrices (predicted by the model and observed with data) rejected. The root mean square error of approximation (RMSEA) was 0.043 (90\% confidence interval - $\mathrm{Cl} 90.0 \%$ of $0.042-0.044$ ), which is an adequate and indicative value of adjusting the model to the factorial structure.. The root mean square residual (RMR) value was 0.023 , i.e., it was within the standard $(<0.10)$. The standardized root mean residual square (SRMR) value was 0.056 , also demonstrating the model's adjustment to the factorial structure. The Goodness of Fit Index found at 0.69 was less than the recommended value for an adequate adjustment (0.90). The incremental adjustment measures were Tucker-Lewis Indexes (TLI), 0.79 and Comparative Fit Indexes (CFI), 0.80, that is, less than the recommended 0.90 value. Thus, the instrument's tetrafactorial dimensional structure proved to be adequate for assessing the investigated construct.

For validity of known groups, the scores of the dimensions of $\mathrm{N}-\mathrm{CT}-4$ Practice were compared between groups defined by variables hospitals with longest and shortest time of Nursing Process implementation, attending master's and doctoral courses (stricto sensu graduate studies), attending training on research use in practice and in search for scientific evidence and reading scientific articles (Table 2 )

Table 2 - Measures of central tendency and dispersion and effect size for construct validity, considering the variables investigated for the four dimensions of the N-CT 4 Practice, Uberaba, Minas Gerais, Brazil, 2019, $(\mathrm{N}=511)$

\begin{tabular}{|c|c|c|c|c|c|c|c|c|c|c|c|c|c|c|c|c|c|}
\hline & \multirow[t]{2}{*}{$\mathbf{n}$} & \multicolumn{4}{|c|}{ Personal } & \multicolumn{4}{|c|}{ Intellectual and Cognitive } & \multicolumn{4}{|c|}{$\begin{array}{l}\text { Interpersonal and } \\
\text { Self-Management }\end{array}$} & \multicolumn{4}{|c|}{ Technical } \\
\hline & & $\overline{\mathbf{x}}$ & $\mathbf{s}$ & $\begin{array}{c}p \\
\text { value }\end{array}$ & d & $\overline{\mathbf{x}}$ & $\mathbf{s}$ & $\begin{array}{c}p \\
\text { value }\end{array}$ & d & $\overline{\mathbf{x}}$ & $\mathbf{s}$ & $\begin{array}{c}p \\
\text { value }\end{array}$ & d & $\overline{\mathbf{x}}$ & s & $\begin{array}{c}p \\
\text { value }\end{array}$ & d \\
\hline \multicolumn{18}{|c|}{ Nursing Process implementation } \\
\hline Pioneer & 94 & 126.6 & 12.95 & \multirow{2}{*}{0.002} & \multirow{2}{*}{0.36} & 157.2 & 14.1 & \multirow{2}{*}{$<0.001$} & \multirow{2}{*}{0.59} & 73.6 & 7.3 & \multirow{2}{*}{$<0.001$} & \multirow{2}{*}{0.55} & 22.0 & 2.3 & \multirow{2}{*}{$<0.001$} & \multirow{2}{*}{0.58} \\
\hline Others & 417 & 122.0 & 12.49 & & & 148.0 & 15.7 & & & 68.9 & 8.6 & & & 20.6 & 2.5 & & \\
\hline \multicolumn{18}{|c|}{ Attending stricto sensu graduate studies } \\
\hline Yes & 140 & 124.6 & 12.98 & \multirow{2}{*}{0.064} & \multirow{2}{*}{0.18} & 152.2 & 16.0 & \multirow{2}{*}{0.031} & \multirow{2}{*}{0.21} & 71.1 & 8.2 & \multirow{2}{*}{0.04} & \multirow{2}{*}{0.20} & 21.5 & 2.5 & \multirow{2}{*}{0.001} & \multirow{2}{*}{0.57} \\
\hline No & 371 & 122.3 & 12.54 & & & 148.8 & 15.6 & & & 69.3 & 8.6 & & & 20.6 & 2.5 & & \\
\hline \multicolumn{18}{|c|}{$\begin{array}{l}\text { Attending training on research use in } \\
\text { practice }\end{array}$} \\
\hline Yes & 79 & 126.3 & 11.19 & \multirow{2}{*}{0.009} & \multirow{2}{*}{0.32} & 154.9 & 14.9 & \multirow{2}{*}{0.001} & \multirow{2}{*}{0.39} & 71.6 & 7.9 & \multirow{2}{*}{0.043} & \multirow{2}{*}{0.25} & 21.3 & 2.5 & \multirow{2}{*}{0.109} & \multirow{2}{*}{0.20} \\
\hline No & 432 & 122.2 & 12.86 & & & 148.7 & 15.8 & & & 69.5 & 8.6 & & & 20.8 & 2.5 & & \\
\hline $\begin{array}{l}\text { Attending } \\
\text { scientific e }\end{array}$ & & & & & & & & & & & & & & & & & \\
\hline Yes & 243 & 123.9 & 12.18 & & & 151.7 & 16.1 & & & 70.8 & 8.2 & & & 21.2 & 2.5 & & \\
\hline No & 268 & 121.9 & 13.09 & 0.002 & 0.16 & 147.9 & 15.3 & $<0.001$ & 0.24 & 68.9 & 8.7 & $<0.001$ & 0.21 & 20.6 & 2.5 & $<0.001$ & 0.24 \\
\hline Reading sc & & & & & & & & & & & & & & & & & \\
\hline Yes & 463 & 123.7 & 12.71 & $<0,001$ & 070 & 150.6 & 15.7 & $<0.001$ & 0.63 & 70.3 & 8.4 & $<0.001$ & 0.65 & 21.0 & 2.5 & $<0.001$ & 0.83 \\
\hline No & 47 & 114.9 & 9.55 & $<0.001$ & 0.70 & 140.8 & 14.1 & & & 64.9 & 8.0 & & & 19.0 & 2.2 & & \\
\hline
\end{tabular}

Note: $\bar{x}$ - mean; s - standard deviation; $d$ - effect size (Cohen's $d$ ). 
The CT skill level was significantly higher for the four dimensions in the hospital whose Nursing Process implementation was pioneering, for nurses who undertook training seeking scientific evidence and for those who read scientific articles.

Nurses with master's degree and PhD had the best level of CT skills for Intellectual and Cognitive $(p=0.031 ; d=0.21)$, Interpersonal and Self-Management $(p=0.041 d=0.20)$ and Technical $(p<0.001)$ dimensions; $d=0.57$ ), when compared to nurses who did not have attend a stricto sensu graduate program. Nurses who undertook training using scientific research in practice had significantly higher scores in Personal $(p=0.009 ; d=0.32)$, Intellectual and Cognitive $(p=0.001 ; d=0.39)$ and Interpersonal and Self-Management dimensions $(p=0.043 ; d=0.25)$, when compared to those who did not attend this type of training.

Regarding the evaluation of the magnitude of the effect, assessed by Cohen's d, it is understood that the greater the effect, the greater the impact of a characteristic favorable to the level of CT skills. Reading articles and time taken to implement the Nursing Process had a greater impact on developing CT skills, with effect size being shown as moderate and large.

Adequate internal consistency was found, since the adapted version of N-CT-4 Practice had a Cronbach's alpha of 0.97 , with a variation from 0.78 to 0.95 between dimensions.

As for test-retest reliability of all dimensions, statistically significant correlations were obtained with ICC values ranging from 0.73 to 0.84 , which confirm instrument reliability (Table 3).

Table 3 -Test-retest reliability of N-CT-4 Practice according to dimensions, Uberaba, Minas Gerais, Brazil, 2019, (N=511)

\begin{tabular}{lccccccc}
\hline Dimensions & \multicolumn{2}{c}{ Test } & \multicolumn{2}{c}{ Retest } & CCI & r & p value \\
\hline $\begin{array}{lccccccc}\text { Personal } \\
\text { Intellectual }\end{array}$ & 123.69 & 11.8 & 121.02 & 11.02 & 0.78 & 0.73 & $<\mathbf{0 . 0 0 1}$ \\
$\begin{array}{l}\text { and Cognitive } \\
\begin{array}{l}\text { Interpersonal } \\
\text { and Self- }\end{array}\end{array}$ & 147.37 & 12.45 & 148.19 & 12.20 & 0.80 & 0.81 & $<\mathbf{0 . 0 0 1}$ \\
$\begin{array}{l}\text { Management } \\
\text { Technical }\end{array}$ & 68.91 & 6.63 & 68.74 & 6.78 & 0.73 & 0.61 & $<\mathbf{0 . 0 0 1}$ \\
Total & 20.30 & 2.35 & 20.33 & 2.45 & 0.77 & 0.58 & $<\mathbf{0 . 0 0 1}$ \\
& 360.26 & 28.68 & 358.28 & 29.01 & 0.84 & 0.81 & $<\mathbf{0 . 0 0 1}$
\end{tabular}

Note:ICC-Intraclass Correlation Coefficient; $r$-Pearson's Correlation Coefficient; $\bar{x}$-mean; s-standard deviation.

\section{DISCUSSION}

The scientific literature demonstrates a lack of methodological studies with NCT-4 Practice. A methodological study carried out in Vietnam was identified using the instrument in English, which was considered valid and reliable for Vietnamese nurses ${ }^{(14)}$.

In the present investigation ${ }^{(15)}$, reliability was assessed using the ICC and Pearson's coefficient, with ICC values (0.73 to 0.84 ) similar to those of the pioneer study $(0.70$ to 0.84$)$. These values indicate good instrument temporal stability ${ }^{(7)}$.

Attending strico sensu graduate courses, used as a criterion for the assessment of known groups, was not prevalent (26.9\%), unlike other studies in which most nurses had master's degree and $\mathrm{PhD}(51.0 \% ; 72.7 \%)^{(7,16)}$.

The mean CT score within the moderate skill level for this type of thinking was also found in a study that sought to assess the difference between such levels of assisting and management nurses and in a study of the relationship between $C T$ and sociodemographic factors ${ }^{(16-17)}$. The moderate level of $C T$ was also a result of other studies carried out with nurses, but which used other assessment instruments ${ }^{(18-19)}$.

In this work, as well as in a pioneer, the results presented by factor analysis demonstrated good dimensional validity in three adjustment variables, RMSEA, RMR, and SRMR ${ }^{(7)}$.

Nurses use their $\mathrm{CT}$ when making a judgment. This process requires a series of $C T$ skills to recognize information and classify priorities in order to understand human responses to a problem. The ability to analyze and reason logically, technical-scientific knowledge, experience in practice with a complete view of the patient and clinical standards, as well as the power of discernment are skills of the PC recognized in the diagnostic process. In this regard, clinical experience and practical knowledge of the Nursing Process work as a basis for understanding clinical manifestations and, consequently, to determinate their relationship with the nursing diagnosis ${ }^{(20)}$. A longer time to implement the Nursing Process was one of the factors that influenced achieving higher CT skill scores.

$\mathrm{CT}$ is considered the main instrument for effective decisionmaking by nurses, being directly related to greater clinical competence and, consequently, to safe and quality care ${ }^{(21-22)}$. Moreover, these skills can be developed through teaching methodologies and facilitating factors in the workplace ${ }^{(21)}$.

Still with regard to validity by known groups, having a master's degree and a PhD, training, and reading of articles were considered factors that significantly influenced CT development.

Longer practice time and development of activities in the Nursing Process positively influence $\mathrm{CT}$ development, a relationship that can be evidenced in studies that used other instruments to measure it, and also demonstrated association of better academic level and attending graduate studies the best CT scores ${ }^{(18,23-25)}$.

In studies that used N-CT-4 Practice, it was also shown that a higher educational level, such as a master's degree, was associated with better levels of skills for $\mathrm{CT}^{(17,26)}$.

Nurses develop their CT in the long term, through a process that must be constantly reinforced. Identifying the groups that present better levels of CT, as well as their associated factors and weaknesses, allows planning effective strategies to develop skills $^{(17)}$. This process of CT improvement implies an increase in nurses' ability to foresee, diagnose and validate findings for later problem-solving. Nurses who work to have their CT skills improved expand clinical, professional, and social competence ${ }^{(27)}$.

\section{Study limitations}

The limitation evidenced was the fact that the model did not fit perfectly with the dimensional structure. This fact can be justified by the high number of items in the instrument, which would require a larger sample size for evidence of a better fit. It is noteworthy, however, that this limitation did not interfere with instrument validation.

\section{Contributions to nursing}

This is a management instrument. It allows planning educational strategies and structural improvements for nursing leaders. In the education field, it can be used to assess teaching methodologies and develop nursing students' CT skills in clinical practice. 
CT skill promotion allows reflecting on the care model and developing actions to improve quality of care and nursing work processes.

\section{CONCLUSIONS}

The Nursing Critical Thinking in Clinical Practice Questionnaire, Brazilian Portuguese version, shows evidence of validity and reliability, and can be used in different Brazilian hospitals, with easy application. Thus, it is suggested to carry out further studies, in different contexts, in order to improve the Brazilian version of the instrument.

\section{FUNDING}

This work was carried out with the support of the Coordination for the Improvement of Higher Education Personnel - Brazil (CAPES).

\section{REFERENCES}

1. Martini JG, Massaroli A, Lazzari DD, Luz JH. Curriculum for undergraduate nursing courses: integrative literature review. Rev Pesqui: Cuid Fundam. 2017;9(1):265-72. https://doi.org/10.9789/2175-5361.rpcfo.v9.4044

2. Colln-Appling CV, Giuliano D. A concept analysis of critical thinking: a guide for nurse educators. Nurse Educ Today. 2017;49:106-9. https:// doi.org/10.1016/j.nedt.2016.11.007

3. Jiménez-Gómez MA, Cárdenas-Becerril L, Velásquez-Oyo la MB, Carrillo-Pineda M, Barón-Díaz LY. Reflective and critical thinking in nursing curriculum. Rev Latino-Am Enfermagem. 2019;27:e3173. https://doi.org/10.1590/1518-8345.2861.3173

4. Azizi-Fini I, Hajibagheri A, Adib-Hajbaghery M. Critical Thinking skills in nursing students: a comparison between freshmen and senior students. Nurs Midwifery Stud. 2015;4(1):e25721. https://doi.org/10.17795/nmsjournal25721

5. Riegel F, Crossetti MGO. Theoretical frameworks and instruments for evaluation of critical thinking in nursing and education. Rev Gaúcha Enferm. 2018;39:e2017-0097. https://doi.org/10.1590/1983-1447.2018.2017-0097

6. Carbogim FC, Barbosa ACS, Oliviera LB, Diaz FBBS, Toledo LV, Alves KR, et al. Educational intervention to improve critical thinking for undergraduate nursing students: a randomized clinical trial. Nurse Educ Pract. 2018;33:121-6. https://doi.org/10.1016/j.nepr.2018.10.001

7. Zuríguel-Perez E, Falcó-Pegueroles A, Roldán-Merino J, Agustino-Rodriguez S, Gómez-Martín MD, Lluch-Canut MT. Development and psychometric properties of the nursing critical thinking in clinical practice questionnaire. Worldviews Evid Based Nurs. 2017;14(4):257-64. https://doi.org/10.1111/wvn.12220

8. Von Elm E, Altman DG, Egger M, Pocock SJ, Gøtzsche PC, Vandenbroucke JP. The Strengthening the Reporting of Observational Studies in Epidemiology (STROBE) Statement: guidelines for reporting observational studies. Ann Intern Med. 2007;147(8):573-7. https://doi. org/10.7326/0003-4819-147-8-200710160-00010

9. Myers ND, Ahn S, Jin Y. Sample size and power estimates for a confirmatory factor analytic model in exercise and sport: a Monte Carlo approach. Res Quart Exerc Sport. 2011;82(3):412-23. https://doi.org/10.1080/02701367.2011.10599773

10. Ferrer M, Alonso J, Prieto L, Plaza V, Monsó E, Marrades R, et al. Validity and reability of the St Geroge's Respiratory Questionaire after adaptation to a different language and culture: the Spanish example. Eur Respir J. 1996;9(6):1160-6. https://doi.org/10.1183/09031936.96.0 9061160

11. Ferreira MBG, Haas VJ, Dantas RAS, Felix MMS, Galvão CM. Cultural adaptation and validation of an instrument on barriers for the use of research results. Rev Latino-Am Enfermagem. 2017;25:1-8. https://doi.org/10.1590/1518-8345.1652.2852

12. Cohen J. Statistical power analysis for the behavioral sciences. 2 ed. New Jersey: Lawrence Erlbaum Associates; 1988. 567p.

13. Fayers PM, Machin D. Quality of life: The assessment, analysis and interpretation of patient-reported outcomes. 2 ed. Chichester/New Jersey: Hoboken/J. Wiley; 2007. 566p.

14. Nguyen TV, Liu H. The Vietnamese Version of the nursing critical thinking in clinical practice questionnaire: translation and psychometric evaluation. Res Square. 2020. Preprint. https://doi.org/10.21203/rs.3.rs-19956/v3

15. OLIVEIRA, J.F. Cultural adaptation and validation of the N-CT-4 Practice instrument: Brazilian Portuguese version, Uberaba [Internet] [Tese]. Uberaba: Universidade Federal do Triângulo Mineiro; 2020 [cited 2021 Mar 12]. Available from: https://sucupira.capes.gov.br/sucupira/ public/consultas/coleta/trabalhoConclusao/viewTrabalhoConclusao.xhtml?popup=true\&id_trabalho=9414691\#

16. Zuríguel-Perez E, Lluch-Canut MT, Agustino-Rodríguez S, Gómez-Martín MD, Roldán-Merino J, Falcó-Pegueroles A. Critical thinking: a comparative analysis between nurse managers and registered nurses. J Nurs Manag. 2018;26(8):1083-90. https://doi.org/10.1111/jonm.12640

17. Zuríguel-Perez E, Falcó-Pegueroles A, Agustino-Rodríguez S, Gómez-Martín MD, Roldán-Merino J, Lluch-Canut MT. Clinical nurses's critical thinking level according to sociodemographic and professional variables (Phase II): a correlational study. Nurse Educ Pract. 2019;41:1-7. https://doi.org/10.1016/j.nepr.2019.102649

18. Ludin SM, Does good critical thinking equal effective decision-making among critical care nurses? A cross-sectional survey. Intensive Crit Care Nurs. 2018,44:1-10. https://doi.org/10.1016/j.iccn.2017.06.002

19. Wu D, Luo Y, Liao X. Correlation between critical thinking disposition and mental self-supporting ability in nursing undergraduates: a crosssectional descriptive study. J Nurs Res. 2017;25(1):68-75. https://doi.org/10.1097/jnr.0000000000000140 
20. Bittencourt GK, Crossetti MG. Critical thinking skills in the nursing diagnosis process. Rev Esc Enferm USP. 2013;47(2):341-7. https://doi. org/10.1590/s0080-62342013000200010

21. Luiz FS, Vasconcellos LJ, Barbosa ACS, Paiva ACPC, Santos KB, Sanhudo NF, et al. Role of critical thinking in nurses'decision making: integrative review. Rev Eletron Acervo Saúde. 2020;38:1-10. https://doi.org/10.25248/reas.e1763.2020

22. Tajvidi M, Moghimi Hanjani S. The relationship between critical thinking and clinical competence in nurses. Strides Dev Med Educ. 2019;16(1):1-7. https://doi.org/10.5812/sdme.80152

23. Drennan J. Critical thinking as an outcome of a Master's degree in Nursing programme. J Adv Nurs. 2010;66(2):422-31. https://doi. org/10.1111/j.1365-2648.2009.05170.x

24. Pitt $V$, Powis $D$, Levett-Jones $T$, Hunter $S$. The influence of critical thinking skills on performance and progression in a pre-registration nursing program. Nurse Educ Today. 2015;35(1):125-31. https://doi.org/10.1016/j.nedt.2014.08.006

25. Ozcan H, Elkoca A. Critical thinking skills of nursing candidates. Int J Caring Sci. 2019;12(3),600-606. https://doi.org/10.1111/jjns.12240

26. Zuriguel Pérez E, Lluch Canut MT, Falcó Pegueroles A, Puig Llobet M, Moreno Arroyo C, Roldán Merino J. Critical thinking in nursing: Scoping review of the literature. Int J Nurs Pract. 2015;21(6):820-30. https://doi.org/10.1111/ijn.12347

27. Carvalho EC, Oliveira-Kumakura ARS, Morais SCRV. Clinical reasoning in nursing: teaching strategies and assessment tools. Rev Bras Enferm. 2017;70(3):662-8. https://doi.org/10.1590/0034-7167-2016-0509 